\title{
Pharmacological comparison of four biopolymeric natural gums as hemostatic agents for management of bleeding wounds: preliminary in vitro and in vivo results
}

\author{
Himanshu Kushwah ${ }^{1}$, Nidhi Sandal ${ }^{2}$, Meenakshi Chauhan ${ }^{3}$ and Gaurav Mittal ${ }^{1 *}$ (i)
}

\begin{abstract}
Background: Uncontrolled bleeding is one of the primary reasons for preventable death in both civilian trauma and military battle field. This study evaluates in vitro and in vivo hemostatic potential of four biopolymeric natural gums, namely, gum tragacanth, guar gum, xanthan gum, and gum acacia. In vitro evaluation of whole blood clotting time and erythrocyte agglutination assay were carried out. In vitro cytotoxicity studies with respect to each gum were done in human lymphocytes to ascertain percent cell viability. In vivo hemostatic potential of each gum (as sponge dressing and powder form) was evaluated in Sprague Dawley rats using tail bleeding assay and compared with commercially available hemostatic sponge. Other important parameters like (a) time taken for complete hemostasis, (b) amount of blood absorbed, (c) adherence strength of developed hemostatic dressing(s), (d) incidence of re-bleeding, and (e) survival of animals were also studied.
\end{abstract}

Results: Of the four test gums studied, xanthan gum (@3mg/ml of blood) and gum tragacanth (@35mg/ml of blood) were able to clot blood in least time $(58.75 \pm 6.408 \mathrm{~s}$ and $59.00 \pm 2.082 \mathrm{~s}$, respectively) and exhibited very good hemostatic potential in vitro. Except for xanthan gum, all other test gums did not exhibit any significant cytotoxicity at different time points till $24 \mathrm{~h}$. In rat tail bleeding experiments, gum tragacanth sponge dressing and powder achieved hemostasis in least time (156.2 $\pm 12.86 \mathrm{~s}$ and $76 \pm 12.55 \mathrm{~s}$, respectively) and much earlier than commercially available product (333.3 $\left.\pm 38.84 s ; p^{<} 0.01\right)$.

Conclusion: Results indicate potential of gum tragacanth to be developed into a suitable hemostatic product. Keywords: Biopolymeric natural gums, Gum tragacanth, Hemostatic potential, Hemagglutination, Cytotoxicity

\footnotetext{
*Correspondence: gauravmittal23@gmail.com; gaurav@inmas.drdo.in

'Department of Combat Sciences, Institute of Nuclear Medicine and Allied Sciences, Defence Research and Development Organisation, Brig. SK

Mazumdar Road, New Delhi 110 054, India

Full list of author information is available at the end of the article
}

\section{Springer Open}

(0) The Author(s). 2021 Open Access This article is licensed under a Creative Commons Attribution 4.0 International License, which permits use, sharing, adaptation, distribution and reproduction in any medium or format, as long as you give appropriate credit to the original author(s) and the source, provide a link to the Creative Commons licence, and indicate if changes were made. The images or other third party material in this article are included in the article's Creative Commons licence, unless indicated otherwise in a credit line to the material. If material is not included in the article's Creative Commons licence and your intended use is not permitted by statutory regulation or exceeds the permitted use, you will need to obtain permission directly from the copyright holder. To view a copy of this licence, visit http://creativecommons.org/licenses/by/4.0/. 


\section{Background}

In spite of advances in medical care in recent years, uncontrolled bleeding or hemorrhage still remains one of the primary causes of preventable death in civilian and combat trauma situations [1,2]. Although during the last couple of decades, a number of topical hemostatic products like HemCon ${ }^{\oplus}$, Celox ${ }^{\oplus}$ Gauze, Chito-SAM $^{\oplus}$, and QuickClot ${ }^{\oplus}$ have been developed $[3,4]$, pre-clinical studies and case reports have revealed some limitations for most of these agents $[5,6]$. Few recently developed dressings are engineered with human coagulation factors, resulting in expensive formulations with low stability [7].

In India, there are no affordable in situ hemostatic agents, which have been developed indigenously. The hemostatic dressings, especially for military and paramilitary personnel engaged in combat roles, are presently imported at an exorbitant cost and consequently much of the demand remains largely unfulfilled. Thus, there is an urgent need to develop an indigenous, efficacious and cost-effective hemostatic product for managing combatrelated hemorrhage in Indian troops.

Hemostatic agents are known to exert their effect through one of the three mechanisms: as mucoadhesive agents (e.g., chitosan-based products), coagulation factor concentrators (e.g., zeolite based QuickClot ${ }^{\ominus}$ ) or coagulation factor supplementors (e.g., fibrin-based products). Recently, there has been some interest among pharmaceutical experts in exploring hemostatic behavior of biopolymeric natural gums, mainly owing to their absorbent nature, high viscosities at relatively lower concentrations, easy availability and cost-effectiveness $[8,9]$. In the present study, we have compared hemostatic effect of four biopolymeric gums, namely, gum tragacanth (GT), xanthan gum (XG), guar gum (GG), and gum acacia (GA) under in vitro and in vivo conditions. Following parameters were evaluated with respect to each of the four gums: in vitro whole blood clotting time, in vitro cytotoxicity, and in vivo hemostatic potential in experimental animals. Concentration of calcium ions, being an integral part of the natural blood coagulation cascade, was also optimized and added into the test compositions in the form of calcium gluconate, so as to accelerate the activation of blood clotting process. We hypothesize that these gums can potentially act as factor concentrators in exerting their pro-coagulant effect.

\section{Materials and methods Materials}

The four test gums were purchased from Merck Pvt. Ltd., Mumbai, India. Roswell Park Memorial Institute Medium (RPMI)-1640 medium, Histopaque ${ }^{\oplus}-1077$ and Thiazolyl-blue-tetrazolium-bromide (MTT), 4-(2-hydroxyethyl)-1-piperazine ethanesulfonic acid (HEPES) were obtained from Sigma-Aldrich, St. Louis, USA. Surgispon $^{\oplus}$, used as comparative positive control dressing, was purchased from local market. All other chemicals were of analytical grade.

\section{Ethics statement}

All animal procedures and care protocols were followed as per the guidelines of Committee for the Purpose of Control and Supervision of Experiments on Animals (CPCSEA) regulations and the experimental protocol was approved by the Institutional Animal Ethics Committee vide approval no. INM/IAEC/2018/23.

\section{Experimental animals}

Sprague Dawley (SD) male rats weighing 200-250g were obtained from Experimental Animal Facility of the institute. All animals were housed in standard environmental conditions of temperature $\left(21-24{ }^{\circ} \mathrm{C}\right)$, humidity $(45-50 \%)$, and a $12 \mathrm{~h}$ light and $12 \mathrm{~h}$ dark cycle in polypropylene cages and were provided with standard feed (Golden Feed Ltd., Delhi, India) and water ad libitum.

\section{In vitro studies}

\section{Determination of whole blood clotting time}

In vitro blood clotting time was measured using the Lee and White method [10]. One milliliter of anticoagulated fresh whole blood was collected in glass tubes from the retro-orbital plexus of healthy Sprague Dawley rats and treated with varying concentrations of each of the four test gums (range, 7-35 mg/ml for GT; $1-4 \mathrm{mg} / \mathrm{ml}$ for XG; $1-8 \mathrm{mg} / \mathrm{ml}$ for $\mathrm{GG}$; and $1-20 \mathrm{mg} / \mathrm{ml}$ for $\mathrm{GA}$ ) in combination with a fixed amount of optimized calcium gluconate $(10 \mathrm{mg} / \mathrm{ml})$ for determining concentration of gum required for clotting of blood in least time. Tube contained blood without any anticoagulant taken as control. The tubes were tilted at $45^{\circ}$ angle every $30 \mathrm{~s}$ to check for blood clot formation and the time taken for clotting was noted. The experiment was repeated five times for each of the test material.

\section{Erythrocyte hemagglutination assay}

Erythrocyte hemagglutination assay was carried out by the method reported by Pogorielov et al. [11]. Five milliliters of blood from the retro-orbital plexus of healthy Sprague Dawley rats was pooled in 10\% potassium ethylene diamine tertaacetic acid (EDTA)-coated tubes. The tubes were centrifuged to separate erythrocytes. Separated erythrocytes were washed 3 times with phosphate-buffered saline (PBS, $\mathrm{pH}$ 7.4) to remove any leucocytes, plasma, platelets, and other cell debris. One milliliter of erythrocytes mass was then suspended in 19 $\mathrm{ml} \mathrm{PBS}$ to make $5 \%$ erythrocyte dilution. Fifty microliters of this dilution was transferred to " $U$ " bottom 96well microplates and treated with sample gum solutions 
in a ratio of 1:1. The sample solutions contained varying concentration of each of the four test gum; viz., 0.5, 0.1, 0.01 , and $0.001 \%$, while control wells contained only PBS. The microplates were incubated at $37{ }^{\circ} \mathrm{C}$ for $1 \mathrm{~h}$ and visual and photographic evaluation was done. The experiments were performed in triplicates.

\section{In vitro cytotoxicity study}

Any potential cytotoxicity of the four biopolymeric gums was evaluated in isolated human lymphocytes using the standard 3-(4,5-dimethyl-2-thiazolyl)-2,5-diphenyltetrazolium bromide (MTT) assay [12]. Lymphocytes were isolated from whole blood by density gradient centrifugation method using Histopaque ${ }^{\ominus}-1077$ and cultured in RPMI 1640 media containing 10\% fetal bovine serum, $100 \mathrm{unit} / \mathrm{ml}$ penicillin, $100 \mu \mathrm{g} / \mathrm{ml}$ streptomycin and buffered with HEPES. The cells were seeded into 96-well plates at a density of $1 \times 10^{4}$ per well and incubated for $24 \mathrm{~h}$ at $37{ }^{\circ} \mathrm{C}$ in a humidified atmosphere containing $5 \%$ carbon dioxide. After incubation, the cells were treated with autoclaved solution of the four test gums separately in varying concentrations $(0.5,0.1,0.01$, and $0.001 \%)$ for different time intervals, i.e., $1 \mathrm{~h}, 4 \mathrm{~h}, 16 \mathrm{~h}$, and $24 \mathrm{~h}$. The samples were treated with $10 \mu \mathrm{l}$ of $5 \%$ MTT solution in $\mathrm{PBS}$ at the respective time intervals and incubated for 4 $\mathrm{h}$ at $37^{\circ} \mathrm{C}$ for the formazan crystals to be formed. After incubation, the precipitated formazan crystals were dissolved in dimethyl sulfoxide (DMSO) and again incubated for $20 \mathrm{~min}$ for the colored product to be formed. The readings were recorded using enzyme-linked immunesorbent assay (ELISA) plate reader at a wavelength of $570 \mathrm{~nm}$ and percent cell viability was calculated for all the samples.

\section{In vivo experiment: evaluation of hemostatic potential in Sprague Dawley rats}

In vivo hemostatic potential of the four gums, GT, GG, GA, and XG was evaluated in Sprague Dawley (SD) rats using tail bleeding model as reported earlier by Sogut et al. [13]. Sixty healthy SD rats (200-250g) were randomly selected by using simple randomization method and assigned in ten groups of 6 rats each as mentioned below. The assessment was carried out in a non-blinded manner.

Group I: Treated with plain sponge without any coating; negative control

Group II: Treated with Surgispon, a marketed hemostatic sponge; positive control

Group III: Treated with gum tragacanth (420 mg)-CG coated sponge

Group IV: Treated with gum tragacanth (420 mg)-CG in powder form

Group V: Treated with xanthan gum (36mg)-CG coated sponge
Group VI: Treated with xanthan gum (36mg)-CG in powder form

Group VII: Treated with guar gum (96 mg)-CG coated sponge

Group VIII: Treated with guar gum (96 mg)-CG in powder form

Group IX: Treated with gum acacia (60 mg)-CG coated sponge

Group X: Treated with gum acacia $(60 \mathrm{mg})-\mathrm{CG}$ in powder form

For preparing gum-coated sponge dressings, commercially available sponge material was taken and cut in circular shapes of $4 \mathrm{~cm}$ diameter. Each test gum in powder form was individually mixed with $120 \mathrm{mg}$ of calcium gluconate (CG) using a mortar and pestle. The optimized amount of each gum and CG was calculated from the in vitro blood clotting experiment results described in earlier section. Water (q.s.) was added to these mixtures to make them into a thick paste. Using dip coating method, each test gum was individually coated onto different circular sponges. After coating, all sponge dressings were dried in a tray dryer at $37^{\circ} \mathrm{C}$ for $2 \mathrm{~h}$. Finally, gum-coated sponge dressings as well as each gum in simple powder form were evaluated for its hemostatic potential in subsequent rat tail bleeding experiments.

Animals were anesthetized by intraperitoneal injection of ketamine $(80 \mathrm{mg} / \mathrm{kg})$ and xylazine $(10 \mathrm{mg} / \mathrm{kg})$ [14]. Tails of all rats were disinfected using $98 \%$ alcohol. Four centimeters length of tail from the tail tip was amputated longitudinally with the help of a surgical blade. The bleeding tails were immediately covered with respective gum-coated sponge dressing/gum powder. The test material was initially applied along with direct pressure for $30 \mathrm{~s}$. Pressure was then withdrawn and the wound was observed for any reduction in bleeding. Following parameters were studied for the evaluation of hemostatic potential as per previously published literature [15]:

a) Adherence strength of the dressing(s)

b) Time for complete hemostasis

c) Amount of blood absorbed by the dressing(s)

d) Incidence of re-bleeding, if any

e) Survival of animal

At the end of the experiment, animal wounds were cleaned with normal saline and povidone iodine was applied. Antibiotic (Amikacin sulfate @ $80 \mathrm{mg} / \mathrm{kg}$ body weight given through intraperitoneal injection) and analgesic (Diclofenac sodium @ $40 \mathrm{mg} / \mathrm{kg}$ body weight given through subcutaneous injection) treatments were given to the animals for 5 consecutive days followed by dressing with povidone iodine to prevent the occurrence of any infection and pain. Animals were kept under 
observation for 1 week. Thereafter, animals were rehabilitated at the Experimental Animal Facility of the institute for their use in future experiments.

\section{Statistical analysis}

The results were expressed as mean \pm S.D. The data were analyzed statistically using GraphPad Prism 5.00. Statistical analysis was performed by one way ANOVA followed by Tukey's post hoc test. For in vitro cytotoxicity study, the results were analyzed by two way ANOVA followed by Bonferroni test. A value of $p<0.01$ was considered significant in all cases.

\section{Results}

\section{In vitro studies}

\section{Determination of whole blood clotting time}

Figure 1 shows whole blood clotting time results with respect to each of the four test gums and their comparison with control. In vitro whole blood clotting time was significantly reduced when whole blood was treated with xanthan gum (@3 mg/ml) or gum tragacanth (@35 mg/ml) in comparison to untreated control $\left(p^{<} 0.01\right)$. While, xanthan gum took $58.75 \pm 6.41 \mathrm{~s}$ for complete blood clotting, gum tragacanth also showed efficient blood clotting ability in almost similar time $(59.00 \pm 2.08 \mathrm{~s})$. The other two gums, guar gum and gum acacia, were comparatively less efficient in their blood clotting ability.

\section{Erythrocyte hemagglutination assay}

Erythrocyte agglutination assay was performed to check the interaction between blood cells and the four test gums. Degree of hemagglutination was described using the following scale devised by Stavitsky and as reported by Pogorielov et al. [11]:

++++ Compact granular agglutinate

+++ Smooth mat on bottom of well with folded edges

++ Smooth mat on bottom of mat with ragged edges

+ Narrow ring of red around edge of smooth mat

- Discrete red button in center of bottom well

Visual determination indicated a complete hemagglutination index $(++++)$ in $0.5 \%$ solutions of gum tragacanth and xanthan gum. While considerable hemagglutination $(+++)$ was seen in $0.1 \%$ solution of gum tragacanth, a relatively weak agglutination index $(++)$ was observed in $0.1 \%$ solution of xanthan gum. Mild agglutination was also seen in $0.5 \%$ and $0.1 \%$ solutions of guar gum. There was no indication of any hemagglutinate formed (-) in solutions of gum acacia at any of the concentrations studied. Erythrocytes suspended in PBS served as negative control (Table 1).

\section{In vitro cytotoxicity study}

The results of in vitro cell toxicity in lymphocytes indicated no significant cytotoxicity of guar gum, gum tragacanth, and gum acacia at all the concentrations studied $(0.5,0.1,0.01$, and $0.001 \%)$ at different time points till 24
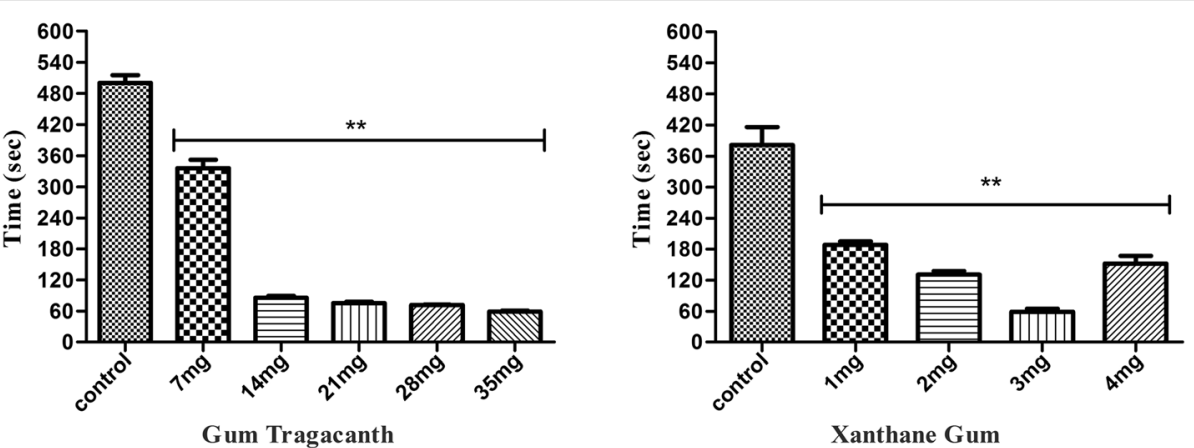

Xanthane Gum
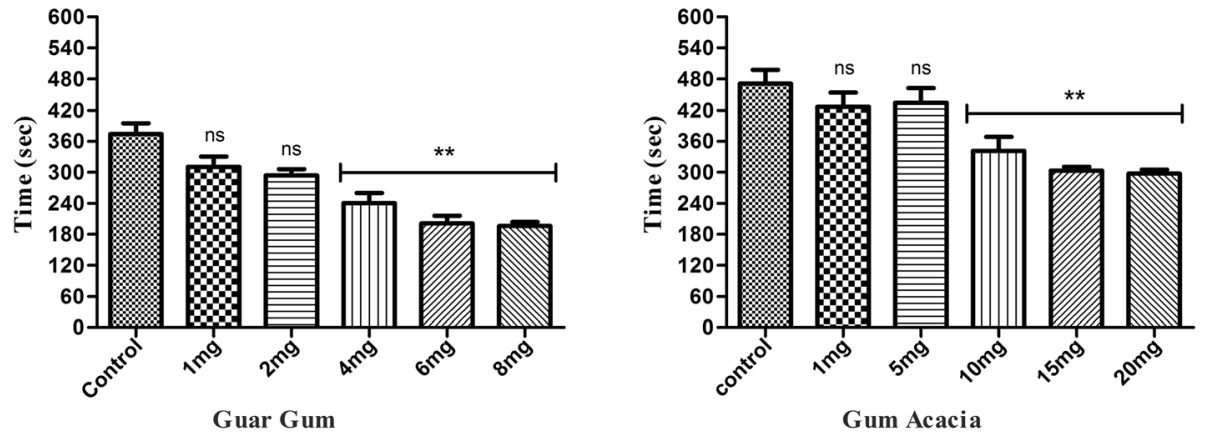

Fig. 1 Effect of individual test gums on in vitro whole blood clotting time. Data is expressed as Mean $\pm S D, n=5$. ${ }^{* *} p^{<} 0.01$ when each test gumtreated group compared with untreated control 
Table 1 Results of in vitro erythrocyte hemagglutination assay in different test gum solutions



*Erythrocytes suspended in PBS-negative control

**There was no indication of any hemagglutinate formed (-) in solutions of GT, XG, and GG at lower concentrations (0.01 and $0.001 \%)$

$\mathrm{h}$, suggesting that these natural gums were not likely to cause any cellular damage on coming in contact with the blood cells. However, some cytotoxicity in terms of cell viability was observed in case of xanthan gum in a concentration and time dependent manner (Fig. 2).

\section{In vivo experiment: evaluation of hemostatic potential in rats}

The results of this study are summarized in Fig. 3. Our data indicates that sponge dressings of xanthan gum and guar gum were comparable to marketed gelatine-based sponge dressing used as positive control in terms of time taken for achieving hemostasis. However, the fastest hemostatic action was exhibited by gum tragacanth powder $(76 \pm 12.55 \mathrm{~s})$ and gum tragacanth sponge dressing $(156.2 \pm 12.86 \mathrm{~s})$, which was significantly better $\left(p^{<} 0.01\right)$ than the marketed product $(333.3 \pm 38.84 \mathrm{~s})$.

Gum tragacanth demonstrated fairly good clot retention when the dressing was removed for checking incidence of re-bleeding in the animals at the site of injury, indicating the likelihood of clot being stable within the dressing. Although gum tragacanth in powder form took
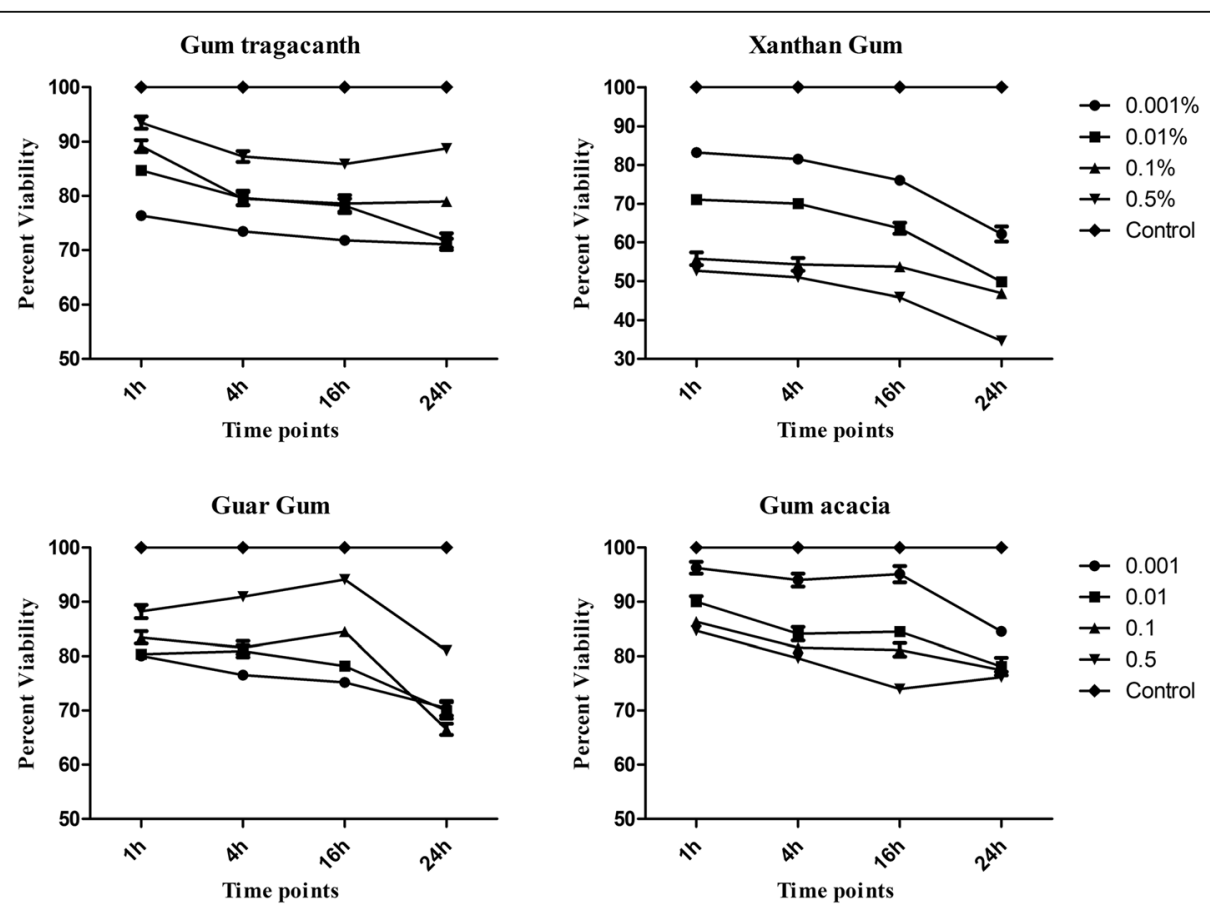

Fig. 2 Results of in vitro cytotoxicity study in lymphocytes with respect to each of the four test gums (GT, XG, GG, and GA) at varying conc. (0.5, $0.1,0.01$, and $0.001 \%$ ). Graph represents the results of three independent experiments (mean $\pm S D$ ), performed in triplicates 


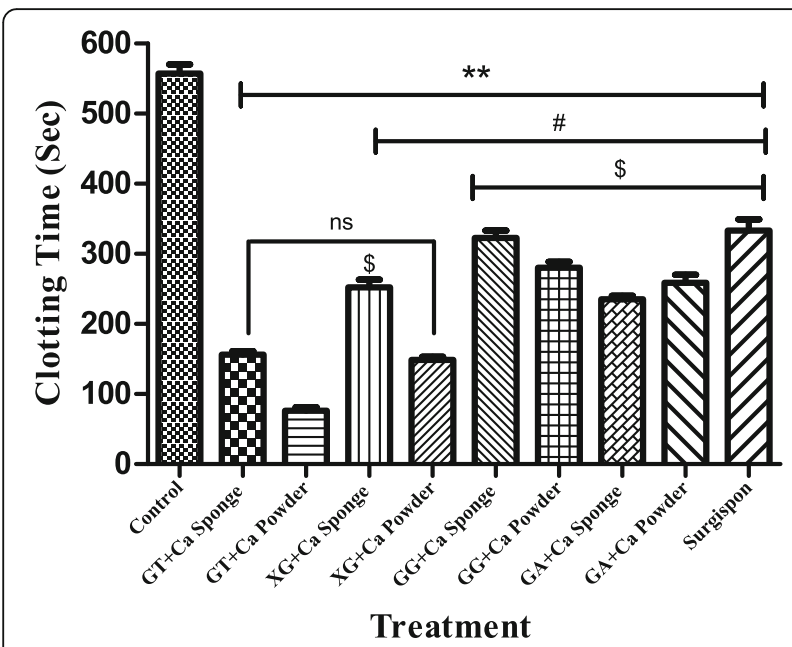

Fig. 3 Graphical representation of in vivo hemostatic potential of the four test gums ( $G T, X G, G G$, and $G A$ ) in sponge and powder forms and their comparison with negative and positive control. Data is expressed as mean $\pm S D, n=6 .{ }^{* *} p^{<} 0.01$ when each test gum/positive controltreated group compared with untreated control; ${ }^{*} p^{<} 0.01$ when gum tragacanth powder-treated group compared with other test gums/ positive control; $p^{<} 0.01$ when gum tragacanth sponge-treated group compared with other test gums/positive control

the least time for achieving hemostasis, it had one major drawback that it adhered to the wound strongly and hence it was difficult to remove it without rupturing the wound. Among the sponge dressings of all the test gums, the adherence strength of gum tragacanth dressing was found to be the best. Other parameters, included in the study like incidence of re-bleeding and survival of animals, are summarized in Table 2. Animals were observed for 1-week post experiment and no occurrence of any infection was seen in the animals.

\section{Discussion}

Use of biopolymeric natural gums as hemostatic materials is being explored with some interest in recent years due to several potential advantages [9]. With this study, we aimed to screen the behavior of four natural gums, viz., gum tragacanth, xanthan gum, guar gum, and gum acacia and compare their hemostatic potential using in vitro and in vivo efficacy parameters.

In vitro whole blood clotting time experiments indicated that of the four natural gums tested, xanthan gum and gum tragacanth showed efficient blood clotting abilities in almost similar times $(58.75 \pm 6.41 \mathrm{~s}$ and $59.00 \pm$ $2.08 \mathrm{~s}$, respectively), while guar gum and gum acacia were less efficient in clotting the blood. In these experiments, the test gums were used in combination with fixed amount of calcium gluconate $(10 \mathrm{mg} / \mathrm{ml})$, conc. of which was optimized in a separate set of experiments (in the range of $2-12 \mathrm{mg} / \mathrm{ml}$ of blood; results not shown). Normal hemostatic process requires calcium ions for most events in the blood coagulation process [16]. Gum tragacanth and xanthan gum probably helped in assimilating the cationic $\mathrm{Ca}^{2+}$ ions and together they were able to clot blood in a significantly lesser time as compared to other groups.

In vitro hemagglutination assay also confirmed the ability of these two gums in agglutinating blood proteins. Results of erythrocyte hemagglutination assay indicating complete agglutination of rat blood cells at higher concentrations of gum tragacanth and xanthan gum, and relatively weak or no agglutination at lower concentrations is consistent with previously reported literature, which suggests that agglutination process is affected by conc. of the test sample [11, 17]. Reason for appearance of hemagglutination in gum tragacanth and xanthan gum could be the presence of more number of protonated groups in these gums, thereby increasing their chances of binding with the erythrocyte wall.

In vitro cytotoxicity experiments were performed since it is important to evaluate the biological behavior of a test material intended to be used in any physiological system. We carried out basic in vitro cell culture study to assess the effect of test gums on cell viability when lymphocytes come in contact with them. So while xanthan gum had exhibited excellent in vitro blood clotting ability during in vitro blood clotting time experiments, it also proved to be cytotoxic to the cells, indicating a major limitation with its use. On the other hand, gum tragacanth was able to clot blood in comparable time as xanthan gum, without inducing any significant cytotoxicity. This observation could be an important advantage while developing gum tragacanth-based hemostatic products. The probable reason for cytotoxicity observed in case of xanthan gum could be attributed to the fact that among all the four gums screened, xanthan gum showed the most viscous behavior in solution, resulting in formation of a thick layer on top of the wells containing lymphocyte cells. This might have hindered oxygen supply to the cells, affecting their viability.

In vivo experiments in experimental animals clearly demonstrated efficacy of gum tragacanth in achieving hemostasis in least time as compared to other gums as well as the marketed product $\left(p^{<} 0.01\right)$. Sorption properties are thought to be important for a hemostatic agent for aggregating blood cells, especially the platelets, at the wound site. However, in our experiments, gum tragacanth-based dressing absorbed significantly lesser amount of blood $(0.14 \pm 0.09 \mathrm{~g})$ as compared to other gums (guar gum, 0.65 $\pm 0.05 \mathrm{~g}$; xanthan gum, $0.56 \pm 0.05 \mathrm{~g}$; gum acacia, $0.29 \pm 0.08 \mathrm{~g})$ and the positive control $(0.60 \pm$ $0.09 \mathrm{~g}$ ), but nonetheless exhibited best hemostatic action. Apparently, sponge dressing of gum tragacanth absorbed less amount of blood as compared to other test gums because it was able to clot blood faster. Therefore in our 





opinion, the amount of blood absorbed by a dressing cannot be taken as a measure for its hemostatic potential. Our observation is supported by similar studies carried out on other hemostatic test materials elsewhere $[1,18]$. The critical parameters therefore should be the time taken for achieving hemostasis and the amount of blood loss during treatment. On both these critical parameters, gum tragacanth was found significantly better than the other three exudates gums as well as the marketed product.

This observed hemostatic behavior of test gums vis-àvis standard plain sponge dressing (negative control) could be due to the fact that while plain sponge dressing after application at the site of injury sorbed plasma and blood cells, the cellular components were not able to adhere to the dressing. Therefore, while the sponge dressing was able to absorb significant amount of blood but no clot formation occurred at the injury site. On the other hand, all the four test gums were probably able to adhere erythrocytes, platelets, and other components of the coagulation cascade on the surface of their respective dressings, while addition of calcium ions helped in the activation of those coagulation factors, thereby facilitating clot formation.

Earlier reports have indicated that efficacy of hemostatic products can be augmented by increasing their viscosity $[19,20]$. Although the exact hemostatic mechanism of these natural exudates gums needs to be elucidated further, we feel that the viscous nature of these gums and the ability to agglutinate blood proteins, especially seen in case of gum tragacanth and xanthan gum, may have also contributed in formation of plugs and the resulting hemostatic efficacy.

Finally, although powder form of gum tragacanth was able to achieve hemostasis in least amount of time; in our opinion, use of gum tragacanth based sponge dressing would still be a better option than the powder form. This is because of the following few basic difficulties we observed during the course of our study, (a) high adherence of the powder form is liable to rupture the wound again if not carefully removed, (b) wastage of drug is less if we use its sponge dressing in place of powder, and (c) in actual field scenario/clinical settings; the ease of applicability would be more for a sponge-based dressing than the powder form because the powder after being applied on to the bleeding wound might still be needed to be covered with a cotton gauze to provide mechanical pressure.

\section{Conclusion}

Results of this study indicate a novel use of gum tragacanth and its potential to be developed into a suitable hemostatic product. Further evaluation including physico-chemical characterization of gum tragacanth coated sponge dressing and its efficacy in large animal bleeding models is needed, the work on which is currently underway in our laboratory.

\section{Abbreviations}

CG: Calcium gluconate; CPCSEA: Committee for the Purpose of Control and Supervision of Experiments on Animals; DMSO: Dimethyl sulfoxide; EDTA: Ethylene diamine tetraacetic acid; ELISA: Enzyme-linked immunesorbent assay; GA: Gum acacia; GG: Guar gum; GT: Gum tragacanth; HEPES: 4-(2-Hydroxyethyl)-1-piperazineethanesulfonic acid; MT: 3-(4,5Dimethyl-2-thiazolyl)-2,5-diphenyltetrazolium bromide; PBS: Phosphatebuffered saline; SD rats: Sprague Dawley rats; XG: Xanthan gum

\section{Acknowledgements}

The authors acknowledge the student research fellowship provided by Council of Scientific \& Industrial Research (CSIR). Authors also thank Director, INMAS for providing necessary facilities to carry out the experimental work.

Studies involving plants must include a statement specifying the local, national or international guidelines and legislation and the required or appropriate permissions and/or licenses for the study Not applicable.

\section{Authors' contributions}

HK performed the experiments. NS and MC helped in planning of in vitro and in vivo experiments. GM analyzed and interpreted the data, besides writing the manuscript. All authors read and approved the final manuscript.

\section{Funding}

The work is part of institutional R\&D project (INM-321) of Defence Research and Development Organization (DRDO), Ministry of Defence, Govt. of India.

Availability of data and materials

The datasets used and/or analyzed during the current study are available from the corresponding author on reasonable request.

\section{Declarations}

Ethics approval and consent to participate

No human studies were involved. All animal procedures and care protocols were followed as per the guidelines of Committee for the Purpose of Control and Supervision of Experiments on Animals (CPCSEA) regulations and the experimental protocol was approved by the Institutional Animal Ethics Committee vide approval no. INM/IAEC/2018/23.

Consent for publication

Not applicable.

\section{Competing interests}

The authors declare that they have no competing interests.

\section{Author details}

${ }^{1}$ Department of Combat Sciences, Institute of Nuclear Medicine and Allied Sciences, Defence Research and Development Organisation, Brig. SK Mazumdar Road, New Delhi 110 054, India. ²Department of CBRN Defence, Institute of Nuclear Medicine and Allied Sciences, Defence Research and Development Organisation, New Delhi 110 054, India. ${ }^{3}$ Delhi Institute of Pharmaceutical Sciences and Research, Delhi Pharmaceutical Sciences and Research University, New Delhi 110 017, India.

Received: 1 December 2020 Accepted: 29 March 2021

Published online: 14 April 2021

References

1. Chan LW, Kim CH, Wang X, Pun SH, White NJ, Kim TH (2016) PolySTATmodified chitosan gauzes for improved hemostasis in external hemorrhage. Acta Biomater 31:178-185. https://doi.org/10.1016/j.actbio.2015.11.017

2. Bennet BL, Littlejohn $L$ (2014) Review of new topical hemostatic dressings for combat casualty care. Mil Med 179(5):497-514. https://doi.org/10.7205/ MILMED-D-13-00199

3. Otrocka-Domagała I, Jastrzębski P, Adamiak Z, Paździor-Czapula K, Gesek M, Mikiewicz M, Rotkiewicz T (2016) Safety of the long-term application of QuikClot combat gauze, ChitoGauze PRO and Celox gauze in a femoral artery injury model in swine - a preliminary study. Pol J Vet Sci 19(2):337343. https://doi.org/10.1515/pjvs-2016-0041 
4. Clay JG, Grayson JK, Zierold D (2010) Comparative testing of new hemostatic agents in a swine model of extremity arterial and venous hemorrhage. Mil Med 175(4):280-284. https://doi.org/10.7205/milmed-d09-00185

5. Khoshmohabat H, Paydar S, Kazemi HM, Dalfardi B (2016) Overview of agents used for emergency hemostasis. Trauma Mon 21(1):e26023. https:// doi.org/10.5812/traumamon.26023

6. Kozen BG, Kircher SJ, Henao J, Godinez FS, Johnson AS (2008) An alternative hemostatic dressing: comparison of CELOX, HemCon and QuikClot. Acad Emerg Med 15(1):74-81. https://doi.org/10.1111/j.1553-2712.2007.00009.x

7. Hickman DA, Pawlowski CL, Sekhon UDS, Marks J, Gupta AS (2018) Biomaterials and advanced technologies for hemostatic management of bleeding. Adv Mater 30(4). https://doi.org/10.1002/adma.201700859 Epub 2017 Nov 22. PMID: 29164804; PMCID: PMC5831165

8. Noh Y, Umeda T, Musha Y, Itatani K (2019) Fabrication of novel bone haemostasis sheet by using sugar-containing hydroxyapatite and plantderived polymer. R Soc Open Sci 6(5):181649. https://doi.org/10.1098/ rsos. 181649

9. Derkach NM (2017) Hemostatic composition. Patent cooperation treaty (PCT) application WO2017060821A1 13 April 2017

10. Wagner WR, Pachence JM, Ristich J, Johnson PC (1996) Comparative in vitro analysis of topical hemostatic agents. J Surg Res 66(2):100-108. https://doi. org/10.1006/jsre.1996.0379

11. Pogorielov M, Kalinkevich O, Deineka V, Garbuzova V, Solodovnik A, Kalinkevich A, Kalinichenko T, Gapchenko A, Sklyar A, Danilchenko S (2015) Haemostatic chitosan coated gauze: in vitro interaction with human blood and in vivo effectiveness. Biomater Res 19(22):1-10. https://doi.org/10.1186/ s40824-015-0044-0

12. Ghosh S, Mukherjee S, Dutta C, Chakraborty K, Gayen P, Jan S, Bhattacharyya D, Roy RS (2017) Engineered isopeptide bond stabilized fibrin inspired nanoscale peptide based sealants for efficient blood clotting. Sci Rep 7(1): 6509. https://doi.org/10.1038/s41598-017-06360-3 PMID: 28747673; PMCID: PMC5529531

13. Sogut O, Erdogan MO, Kose R, Boleken ME, Kaya H, Gokdemir MT, Ozgonul A, lynen I, Albayrak L, Dokuzoglu MA (2015) Hemostatic efficacy of a traditional medicinal plant extract (Ankaferd blood stopper) in bleeding control. Clin Appl Thromb Hemost 21(4):348-353. https://doi.org/10.1177/1 076029613504129

14. Van Pelt LF (1977) Ketamine and xylazine for surgical anesthesia in rats. J Am Vet Med Assoc 171(9):842-844 PMID: 924855

15. Mohanan PV, Mavely L, Pandya A (2011) Toxicity and hemostatic potential of poly [B-(1, 4)-2-amino-2-deoxy-D-glucosamine] based hemostatic material on albino rabbits. Toxicol Mech Methods 21(1):25-30. https://doi.org/10.31 09/15376516.2010.529185

16. Lippi G, Salvagno GL, Brocco G, Gelati M, Danese E, Favaloro EJ (2017) Impact of experimental hypercalcemia on routine haemostasis testing. PLoS One 12(3):e0175094. https://doi.org/10.1371/journal.pone.0175094 PMID: 28362859: PMCID: PMC5376338

17. de Lima JM, Sarmento RR, de Souza JR, Brayner FA, Feitosa APS, Padilha R et al (2015) Evaluation of hemagglutination activity of chitosan nanoparticles using human erythrocytes. Biomed Res Int:247965. https://doi. org/10.1155/2015/247965 Epub 2015 Feb 11. PMID: 25759815; PMCID: PMC4339715

18. Arnaud F, Parreño-Sadalan D, Tomori T, Delima MG, Teranishi K, Carr W, McNamee G, McKeague A, Govindaraj K, Beadling C, Lutz C (2009) Comparison of 10 hemostatic dressings in a groin transection model in swine. J Trauma Acute Care Surg 67(4):848-855. https://doi.org/10.1097/ta. 0b013e3181b2897f

19. Palm MD, Altman JS (2008) Topical hemostatic agents: a review. Dermatol Surg 34(4):431-445. https://doi.org/10.1111/j.1524-4725.2007.34090.x

20. Kuwahara RT, Craig SR, Amonette R (2000) More on Monsel's solution. Dermatol Surg 26:979-980. PMID: 11050511, 10, DOl: https://doi.org/10.1046/ j.1524-4725.2000.026010979.x.

\section{Publisher's Note}

Springer Nature remains neutral with regard to jurisdictional claims in published maps and institutional affiliations.

\section{Submit your manuscript to a SpringerOpen ${ }^{\circ}$ journal and benefit from:}

- Convenient online submission

- Rigorous peer review

- Open access: articles freely available online

- High visibility within the field

- Retaining the copyright to your article

Submit your next manuscript at $\boldsymbol{\nabla}$ springeropen.com 